\title{
Organizational support, identity research on the influence of the new generation peasant workers job satisfaction --Based on migrant workers motivation perspective
}

\author{
Xiupeng Ding a, Lu Ma ${ }^{b}$ \\ School of Management, Guangxi University of Science and Technology, Liuzhou 545006, China \\ adxp930206@126.com, bmalu6655@163.com
}

\begin{abstract}
At present the domestic and foreign studies have shown that perceived organizational support has a positive effect on employees' job satisfaction, and employee identity also has a positive effect on job satisfaction. So the situation in China, the new generation of migrant workers job satisfaction can be from two factors of perceived organizational support and identity, but because of the identity of the new generation migrant workers particularity, can from the perspectives of work motivation analysis to study the mechanism of influence on job satisfaction. This research try to found in previous research: A. perceived organizational support on the new generation of migrant workers job satisfaction has a positive effect. B. perceived organizational support for intermediary bridge by identity of new generation migrant workers job satisfaction has a positive effect. C. workers motivation can regulate influence the new generation migrant workers identity, different workers motivation can make the new generation of migrant workers to identity have different function.
\end{abstract}

Keywords: Organizational support; Sense of personal identification; New generation of migrant workers; Job satisfaction; Work motivation.

\section{Introduction}

With the reform and opening-up, the rapid development of China's social and economic, industrialization and urbanization, the implementation of the policy. A growing number of rural population into cities, according to the country's official statistics, China's migrant population has reached 260 million, of which more than $60 \%$ were born after 1980, in the towns mainly non-agricultural occupations of the rural population, and these people are called new generation migrant workers. These after 80s the new generation peasant workers, unlike their elders. One is the Chunhua Yang pointed out that because of their upbringing, personal appeal, with reference to the target, identification, migrant workers motivation, self-psychological orientation have been fundamental changes in [1]. Two is that Chuanjiang liu research shows that because of their high level of education than their parents, have higher career expectations and desire to integrate into city life, pay more attention to status equal, longing for others to respect and social identity, etc. [2]. Therefore, on the basis of the existing literature, this study innovation point of this study is to organizational support, identity, work motivation theory in the one model, study on the influence mechanism of Cenozoic migrant workers in cities and towns' career satisfaction.

\section{Content}

\subsection{The new generation of migrant workers job satisfaction research status}

At present, the domestic and foreign scholars have generally focused on job satisfaction impact on important of urbanization in the new generation of migrant workers. At abroad, Hellman think that decide the importance of job satisfaction factors mainly includes five aspects, respectively is the job itself, pay, work environment, the harmonious relationship between colleagues, and personality and job matching [3]. Ahituv and Kimhi in China's migrant workers, for example the research shows that the migrant workers to the registered permanent residence and social security system factors such as satisfaction has a significant influence on the migrant workers employment [4]. Thijs and Pan, focusing on the economic factors, the establishment of a general equilibrium model analyzes the 
obstacle factors influencing peasant workers' employment in cities and towns, especially investigates the factors such as capital, migrant wages in cities and towns of urban migrant workers employment behavior influence [5]. Nielsen et al. To use of Personal Welfare Index (PWI) in Fujian province was studied happiness for migrant workers, and from the standard of living, personal health, life, relationships, personal safety, community and future security seven aspects, such as measuring the satisfaction of migrant workers employment in cities and towns [6].

In our country, previous studies have shown that Mingwang Cheng earlier to realize urban factors such as people to transfer decision-making to the leading role of rural migrant workers, put forward "town tension is the core factors that affect urban migrant workers employment" [7]. Yongzheng sun an enterprise 226 migrant workers in southern Jiangsu research shows that in terms of relationship between colleagues and leadership recognition, satisfaction is a bit high, migrant workers in working hours, working environment and meals arrangement, migrant workers have lower satisfaction [8]. Zhi sheng zhang and Fan Cheng pointed out that labor rights abused is one of the important factors affecting migrant workers employment in cities and towns, organization or enterprise need to provide labor protection and can improve the job satisfaction of migrant workers of organizational justice [9]. So, Managers should pay more attention to the new generation of migrant workers job satisfaction, and they have more communication, giving attention and care, they work only can help enterprises to get good development and realize personal value.

\subsection{Perceived organizational support for the influence of the new generation peasant workers job satisfaction}

Eisenberger is put forward for the first time in 1986 by the social exchange theory, the principle of reward and organization to human nature thought breeds organizational support theory, emphasizes the organization's support for employees is the key factors that lead to staff is willing to contribute to the organization [10]. Then he and Rhoades confirmed Perceived Organizational Support, POS, affective Organizational commitment and employee's job satisfaction is connected [11]. Domestic Wenquan Zheng and xiaona guo confirmed that perceived organizational support and employee job satisfaction relationship between coefficients of high [12]. Xiaohong Tan Based on China's 611 of all kinds enterprise staff organizational support, job satisfaction and turnover intention of the study prove that: organizational support significantly positively related to impact on employee job satisfaction in domestic companies also set up [13].

New generation of migrant workers, as a representative of the economic transition period in our country social workers provide new generation migrant workers' rights and interests of labor and social security service system policy, such as value of new generation migrant workers and enterprises or organizations to provide job security, organizational support for the protection of the pay, can promote the emotional connection between them and enterprise.

\subsection{Effect of a sense of identity for the new generation of migrant workers' Job Satisfaction}

Generation of migrant workers are different from their parents, their education level is generally higher than their elders, so pay more attention to be respected and receive fair treatment business. Thus they do not like their parents for a high degree of their farmers' identity, but more inclined to workers' organizations and identities, Camerer study found that economic preferences as social preferences can affect individual utility functions important section, and social preferences including identity, trust, fairness, reciprocity and cooperation [14]. Fehr social preferences from the perspective of the former starting construction of the theoretical model of the final inspection of the identity equivalents, respect for other non-material incentives for individual employees work with state incentive effect [15].

Weiping Qin, Shuming Zhao, who found to enhance the generation of migrant workers of organizational identity can positively affect the work of embedding [16]. Akerlof et al found that, given the staff worker identity, even without the appropriate supervision of work, workers will have a high efficiency of the organization [17]. Chunhua Yang found that when the new generation of migrant workers feel their own social status, and get along with others, the probability of their job satisfaction will greatly enhance [18]. 
So companies can be fair and to strengthen the identity of their organizations and workers' perception of the identity of the new generation of migrant workers, so that the new generation of migrant workers may have greater organizational efficiency improvement.

\subsection{Workers motivation for identity and job satisfaction generation of migrant workers have a regulatory role}

As based on the target set theory (Theory of Goal Setting) Locke E.A. proposed theoretical foundation, the new generation of household registration status of migrant workers is the rural household, the initial purpose or motivation for their migrant workers. There are two, one is money-oriented A is a self-development oriented. Pay more attention to money-oriented wage income, they want to supplement the family income, inner identity is the identity of the farmers. And Herzberg two-factor theory is based on the view that arouse motivation there are two main factors First, health factors, and second motivating factor. Health factors can eliminate people's dissatisfaction. Therefore, enterprises to pay, the higher their job satisfaction. Another self-development-oriented generation of migrant workers want more life into the town, and more concerned about their own future development, which is the motivating factor. Studied by Zhifu Yao translation and other display when they have a desire to work expectations and career development, corporate wages have not obviously affect their job satisfaction, their pursuit of a more equitable treatment, development promotion and personal value positions [ 19].

In the case of expected income is much lower than actual income, if the new generation of migrant workers to the over-emphasis on wages, it is very easy because of the low wages and negate the entire work, resulting in low job satisfaction. Attitude towards urban lifestyles variable regression results show the front of the hypothesis, suggesting that urban lifestyle recognition will help enhance the new generation of migrant workers job satisfaction, high degree of recognition of the urban lifestyle of the new generation of migrant workers not only cherish the city jobs, and are more likely to take the initiative to integrate into urban society, on the job like a duck.

\section{Conclusion and Implications of this study}

\subsection{Conclusion}

Based on previous research literature can be found organizational support is a major factor in the new generation of migrant workers job satisfaction influence on the new generation of migrant workers identity also help to improve the new generation of migrant workers job satisfaction; psychological factors, namely workers motivation also affects the new generation of migrant workers job satisfaction, motivation, personal development, help to improve the new generation of migrant workers job satisfaction; money-oriented generation of migrant workers to their job satisfaction also play an important role.

\subsection{Implications}

Management Implications of this study is: (1) In the new urbanization construction process, in addition to the macro level, improve the household registration system and income distribution system, the majority of employment enterprise by implementing supportive human resource management policies to enhance organizational support migrant workers but also to achieve employment stability, an important means of promoting the integration process of urban migrant workers. (2) Apart from giving foreign companies and employment generation of migrant workers the necessary support for the work, they should be given special care of their life and urban integration support to better achieve organizational support fit. In order to better improve the efficiency of the organization, so that the new generation of migrant workers have more active participation of the organization, become a member of the organization. (3) Enterprises can strengthen the training of the new generation of migrant workers career planning education and job skills to develop the new generation of migrant workers the right attitude to work and life. 


\section{References}

[1] Chunhua Yang .Thoughts on the new generation of migrant workers [J]. Issues in Agricultural Economy, 2010 (4): 80-84.

[2] Zhuanjiang Liu .features of the new generation of migrant workers, the public and the challenges of [J] Population Studies, 2010 (2): 34-39.

[3] M. Hellman. Job Satisfaction and intent to Leave [J].Journal of Social psychology, 1997, 137 (6): 58-64.

[4] Avner Ahituv,Ayal Kimhi.Off-farm Work and Capital Accumulation Decisions of Farmers over the Lifecycle: The role of Heterogeneity and State Dependence[J].Journal of Development Economics,2002,68(2):79-87.

[5] Thijs, Haoran Pan. Competitive Presssures on China: Income Inequality and Migration [J].Regional Science and Urban Economics, 2005, 35 (6): 114-121.

[6] I.Nielsen, R. Smyth, Q. Zhai. Subjective Well-being of Chinese Off-farm Migrants [J].Journal of Happiness Studies, 2010, 11(1):324-335.

[7] Mingwang Cheng, Qinghua Shi, Jianxia Yang Chinese rural labor force due to explain to Mobile with one disorder [J] Economic Research, 2006 (4): 68-78. Empirical Analysis

[8] Yongzheng Sun. migrant workers job satisfaction [J] Chinese Rural Economy, 2006 (1): 42-48. .

[9] Zhisheng Zhang, Cheng Fan. Problem lacking a new generation of women migrant workers' rights [J] Statistics and Decision, 2007 (5): 132-133.

[10]Eisenberger, R., Huntington, R., Hutchison, S., \& Sowa, D. Perceived organizational support [J]. Journal of Applied Psychology, 1986, 71:500- 507.

[11]Rhoades, L., \& Eisenberger, R. Perceived organizational support: a review of the literature [J]. Journal of Applied Psychology, 2002, 87:698- 714.

[12] Wenquan Zheng, Xiaonuo Guo. Organizational support, job satisfaction and job performance ---Finance Research .2010,6 An Empirical Study of University Teachers [J].: 125-129.

[13]Xiaohong Tan, Qiwen Qin, XiaofuPan. companies perceived organizational support and job satisfaction, turnover Intention [J] Psychological Science, 2007,30 (2): 441-443

[14] Camerer, Colin, George Loewenstein. Behavioral Economics: Past, Present, Future [J].Princeton University Press, 2004, 106(3):453-474.

[15]Fehr E, Hart, Zehnder. Contracts, Reference Points and Competition-Behavioral Effects of the Fundamental Transformation [J]. Journal of the European Economic Association, 2009 (7): 561-572.

[16] Weiping Qin, Shuming Zhao. Multiple Identity Justice Generation of migrant workers and work organization Perspective embedded relationship [J] Journal of Management, 2014, 1 (10): 1445-1452.

[17] Akerlof GA, Kranton RE. Identity, Supervision, and Work Groups [J]. American Economic Review, 2008, 98 (2): 212-217.

[18] Chunhua Yang. Thinking about the new generation of migrant workers problem [J] Issues in Agricultural Economy, 2010 (4): 80-84.

[19]Zhi Fu Yao, new generation of migrant workers job satisfaction Factors - Based on survey data in Northwest Province [J] Chinese rural economy .2012, (8): 46-55. 